\title{
Fretting wear in self-piercing riveted aluminium alloy sheet
}

\author{
Y.K. Chen*, L. Han, A. Chrysanthou and J.M. O’Sullivan
}

University of Hertfordshire, Department of Aerospace, Automotive and Mechanical Engineering, Hatfield, Herts. AL10 $9 A B, U K$.

\begin{abstract}
Fretting wear in aluminium alloy AA5754 joined by self-pierce riveting (SPR), a relatively new fastening technique increasingly used in vehicle structures, has been investigated in this paper. Surface damages have been induced when a joint experienced a sinusoidal cyclic tension-tension load. Various degradation zones have been characterised in the contact surfaces between the aluminium sheets, as well as the rivet and the locked sheet. Subsequent examination of the fretting scars at the contact surfaces and through the cross-section has been carried out using optical and scanning electron microscopies. The fretting patterns in the self-piercing riveted joints have been identified. It was noted that fretting wear was initially patchy and layers of compacted debris were created as fretting continued. An Energy Dispersive X-ray (EDX) analysis of the fretting debris from the interface between the rivet and the aluminium sheet revealed the presence of $\mathrm{Al}, \mathrm{Fe}, \mathrm{Si}, \mathrm{C}$ and $\mathrm{O}$ so that it is suggested that intimate mixing of debris from the aluminium alloy and the steel rivet had occurred. The effects of testing conditions such as the load magnitude and the number of loading cycles on the fretting wear patterns were also studied. Metallographic examination has shown that these fretting zones are critical with respect to fretting crack nucleation. The test results have shown that joint fracture initiates at these critical zones.
\end{abstract}

Keywords: Fretting wear, Self-pierce riveting, Aluminium alloy AA5754.

* Corresponding author

\section{Introduction}

Self-pierce riveting technology is a relatively new fastening technique. It has become a potential joining approach for aluminium alloy structures in the automotive industry owing to its unique advantages over conventional fastening methods, such as spot welding[1-3]. However, only a small body of experimental data is available to make possible predictions about the behaviour of a self-pierce riveted aluminium alloy joint [4-5]. In addition, the fretting wear behaviour of self-piercing riveted aluminium alloy sheet has received little attention although it is well known that aluminium alloys have poor fretting wear and fatigue resistance and that the probability of encountering fretting in structures is extremely high [6].

It is well known that fretting occurs between clamped, nominally static contact when subjected to relative motion of a low order of magnitude from 1 to $100 \mu \mathrm{m}$ [7-9]. The presence of fretting can significantly degrade the fatigue life of riveted joints [10]. It has been reported that fretting damage is greatest when there is considerable solubility between dissimilar metals in contact [11]. Previous studies of fretting have been confined to conventional riveted joints. Forsyth [12] indicated that a wear depression under the fastener head could lead to loosening of the joint and result in final fretting fatigue failure. Lyer et al [13] investigated the effect of fretting on fatigue and corrosive wear deterioration of a conventional riveted lap joint and found that serious fretting occurred on the interface between two riveted sheets. Having examined the influence of the process parameters on the fatigue performance of riveted aircraft structures, Szolwinski et al [14] revealed that a higher squeeze force resulted in an increase of fretting damage on the faying surfaces. Schijve [15] reported that fretting corrosion of a riveted joint was significant for the initiation of fatigue cracks. 
This paper presents the existence of fretting wear in AA5754 aluminium alloy joined by self-pierce riveting. The fretting patterns in the contact surfaces between the aluminium sheets, the rivet and pierced sheet as well as the rivet and locked sheet of the self-piercing riveted joints have been identified. It was noted that fretting wear was initially patchy and layers of compacted debris were created as fretting continued. The effects of the testing conditions such as the load magnitude and the number of loading cycles on the fretting wear patterns were also studied. Metallographic examination has shown that these fretting zones are critical with respect to fretting crack nucleation. The test results have shown that joint fractures initiate at these critical zones.

Table 1 Nominal compositions \& properties of HS5754 sheet

\begin{tabular}{|c|c|c|c|c|c|c|}
\hline \multicolumn{7}{|c|}{ Nominal chemical compositions (wt\%) } \\
\hline $\mathrm{Mg}$ & $\mathrm{Mn}$ & $\mathrm{Si}$ & \multicolumn{2}{|c|}{$\mathrm{Cu}$} & $\mathrm{Fe}$ & $\mathrm{Al}$ \\
\hline $2.6-3.6$ & $0-0.5$ & $0-0.4$ & \multicolumn{2}{|c|}{$0-0.1$} & $0-0.4$ & Balance \\
\hline \multicolumn{7}{|c|}{ Mechanical Properties } \\
\hline \multicolumn{2}{|c|}{$\begin{array}{l}\text { Young's Modulus } \\
\text { (GPa) }\end{array}$} & \multicolumn{2}{|c|}{$\begin{array}{l}\text { Tensile strength } \\
(\mathrm{MPa})\end{array}$} & \multicolumn{2}{|c|}{ Elongation } & $\begin{array}{l}\text { Hardness } \\
\left(\mathrm{H}_{\mathrm{V}}\right)\end{array}$ \\
\hline \multicolumn{2}{|c|}{70} & \multicolumn{2}{|l|}{240} & \multicolumn{2}{|c|}{$22 \%$} & 63.5 \\
\hline
\end{tabular}

\section{Experimental procedures}

\subsection{Materials and specimens}

Material specifications are listed in Table 1. Aluminium alloy sheet (AA5754), which was supplied by Alcan International Limited, was pretreated with a thin chromate-based film less than $1 \mu \mathrm{m}$ thick (concentrations of chromium and chromates were far below $0.1 \%$ ). The sheet was also coated with a waxy-based lubricant whose concentration was below 1\%. The thickness of the alloy sheet used in the study was $2 \mathrm{~mm}$. The samples were riveted by Textron Fastening Systems using 36MnB4 rivets with a countersunk head [16]. The rivet had a diameter of $4.5 \mathrm{~mm}$ and a length of $7.0 \mathrm{~mm}$.

As shown in Fig.1, a typical specimen had an effective length of $200 \mathrm{~mm}$, a grip length of $70 \mathrm{~mm}$ on both ends and a width of $60 \mathrm{~mm}$. The sample was loaded in the longitudinal direction that was parallel to the longitudinal grain direction in the aluminium alloy sheet. A typical section of a self-pierce riveted joint is shown in Fig.2.
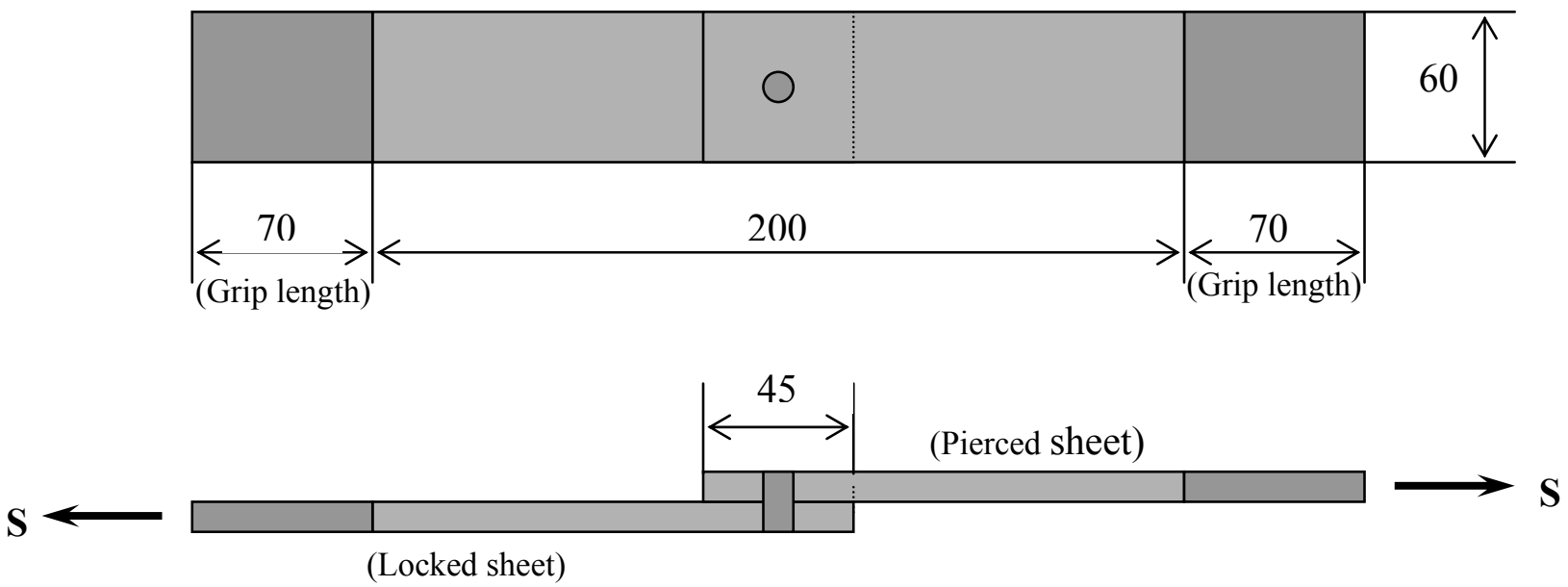

Fig.1 Specimen geometry and the principal cyclic load. (All dimensions in $\mathrm{mm}$ ) 


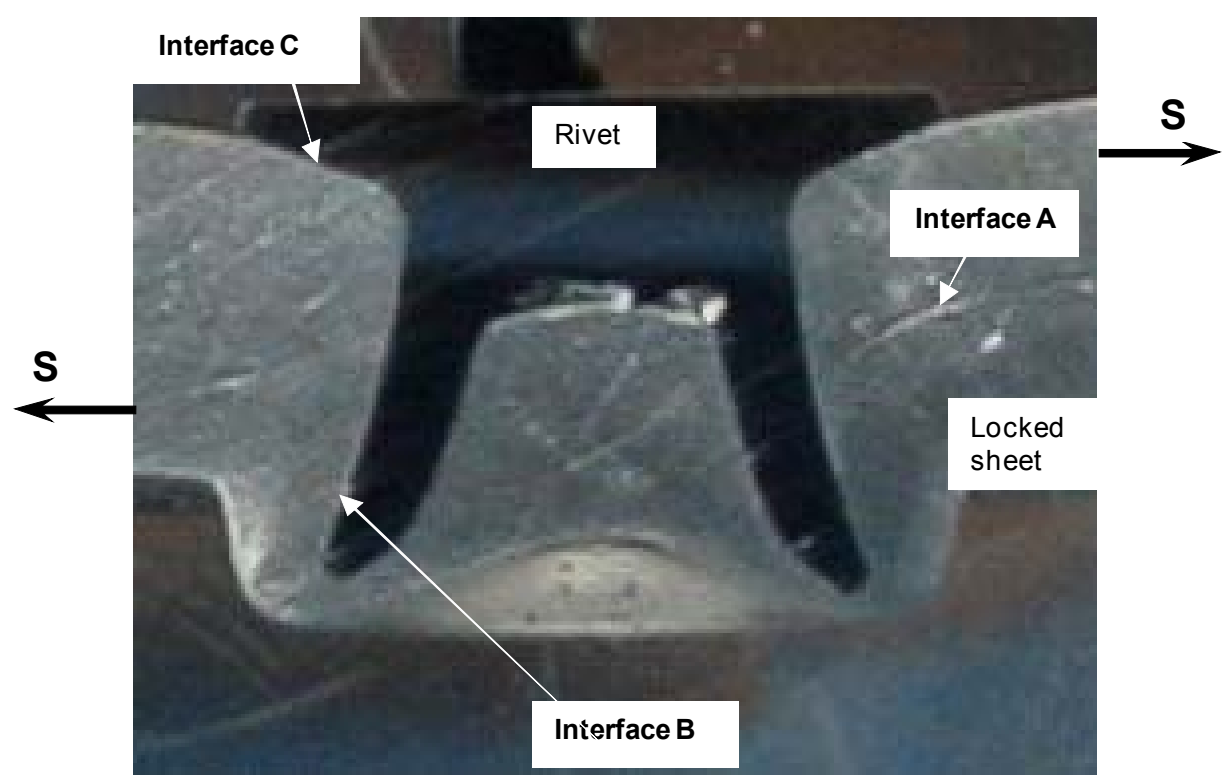

Fig. 2. Section through a self-piercing riveted joint.

\subsection{Testing parameters}

All specimens were tested using a close-loop servo-hydraulic universal test machine. A cyclic tensiontension load with sinusoidal waveform at a nominal frequency of $20 \mathrm{~Hz}$ was employed in the principal cyclic load control so that the testing conditions match those of existing results from different types of joints. Three loading levels were used, which were with maximum loads of $4.5 \mathrm{kN}, 3.6 \mathrm{kN}$ and $2.7 \mathrm{kN}$ respectively and with a minimum load of $0.5 \mathrm{kN}$. At each loading level, besides testing to failure, some tests were stopped at $10 \%, 15 \%$ and $65 \%$ levels of the average fatigue life of a joint. The average fatigue life was determined based on the average number of cycles obtained from five samples tested at a fixed load level. After tests, the wear scars on the joining surfaces between the two sheets and the interfaces between aluminium sheet and rivet were investigated by scanning electron microscopy/energy dispersive X-ray analysis (SEM/EDX). Elemental analysis was carried out at a beam voltage of $20 \mathrm{kV}$.

\section{Results}

\subsection{Fretting between two joined sheets}

Fretting was observed to take place at two different positions of a joint as indicated by points A and B in Fig.2. Figs.3 a)-c) show the fretting regions at the interfaces between the pierced and the locked sheets of three different SPR joints. These fretting regions are marked as interface A in Fig.2. It can be seen that the fretting areas are covered with oxidized wear debris coloured black so that the boundary between the fretting and the non-fretting zones can be clearly distinguished. The fretting regimes vary from 2 to $4 \mathrm{~mm}$ wide and from 5 to $8 \mathrm{~mm}$ long. 


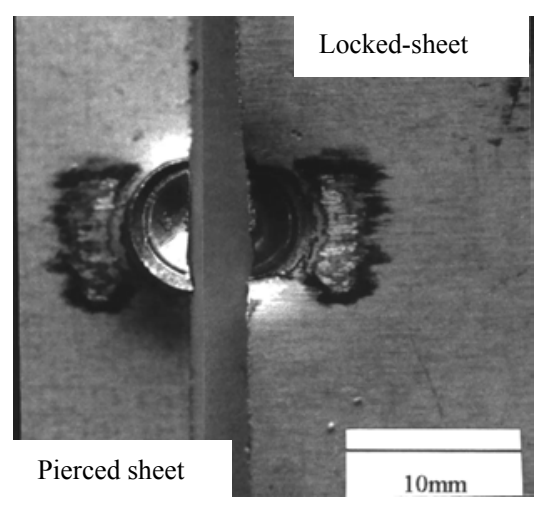

(a)

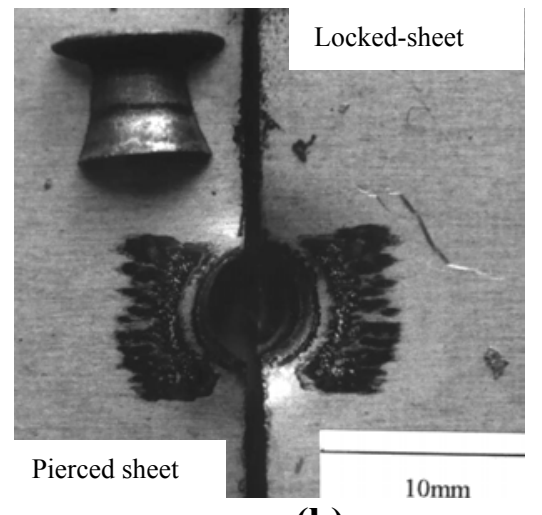

(b)

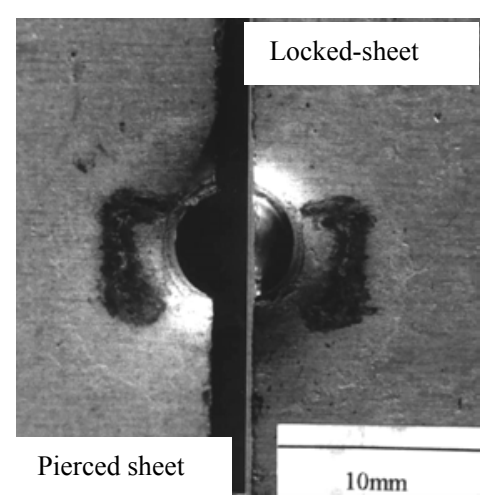

(c)

Fig.3 Fretting regions at the interface between two sheets: (a) for $2.1 \times 10^{4}$ cycles at $4.5 \mathrm{kN}$; (b) for $8.9 \times 10^{4}$ cycles at $4.5 \mathrm{kN}$; (c) for $8.5 \times 10^{5}$ cycles at $2.7 \mathrm{kN}$.

Figs.3a)-c) also show the effects of the total number of cycles and the magnitude of an applied load. As shown in Fig.3a), fretting started to take place after $2.1 \times 10^{4}$ cycles at a maximum load of $4.5 \mathrm{kN}$, which corresponds to $15 \%$ of the total fatigue life of the samples. After $8.9 \times 10^{4}$ cycles under the identical load of $4.5 \mathrm{kN}$, the fretting area was increased producing more fretting debris as shown in Fig.3b). Fig.3c) shows the fretting scars on both sheets around the rivet after $8.5 \times 10^{5}$ cycles at $2.7 \mathrm{kN}$. It is evident that the fretting area of the SPR joint is much smaller than that tested at $4.5 \mathrm{kN}$ for $2.1 \times 10^{4}$ loading cycles shown in Fig.3b) even though the joint shown in Fig.3c) has experienced more than ten times the loading cycles than that shown in Fig.3b).

\subsection{Fretting at the interface between the rivet and the joined sheet}

In addition to fretting at the interface between the pierced and the locked sheet, there was also evidence of a circumferential fretting scar as well as scattered fretting scars on the rivet surface where the rivet was interlocked with the locked sheet, as presented in Fig.4. This is described as interface B in Fig.2. The width of the circumferential fretting scar was approximately $0.5-0.8 \mathrm{~mm}$. EDX analysis revealed the presence of a high aluminium concentration at the fretting scar of the rivet, as shown in Fig.5. Figs.4-5 also show that there is no fretting scar within a region of $2 \mathrm{~mm}$ beneath the rivet head. This region was the contact interface between the rivet and the pierced sheet before the joint had been disassembled and there was no relative motion at this interface[17]. 


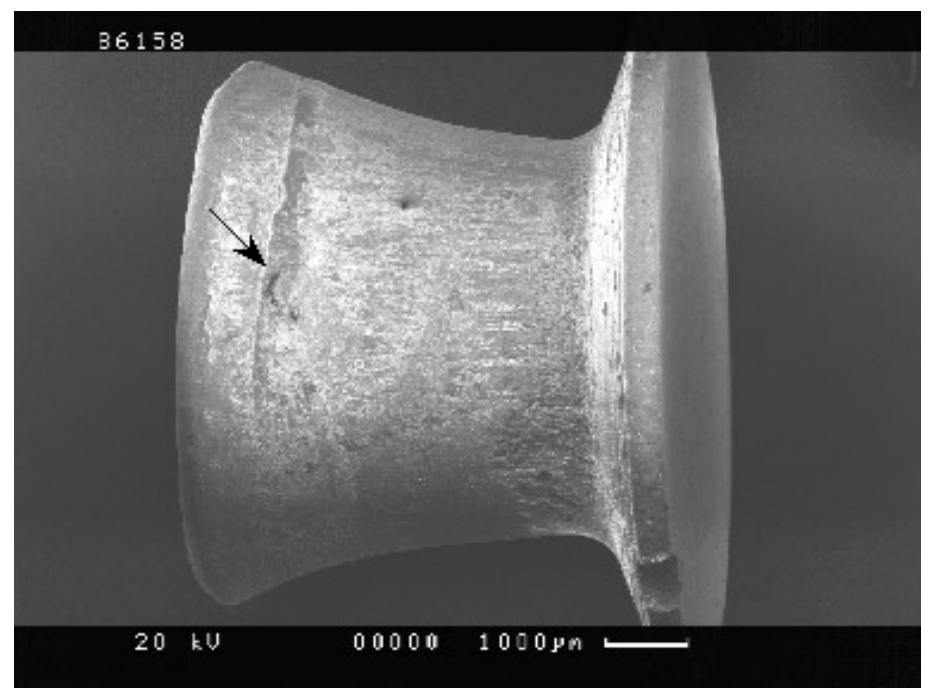

Fig.4 A fretting zone of the rivet in the interface with the locked sheet running at $4.5 \mathrm{kN}$ for $2.1 \times 10^{4}$ cycles.

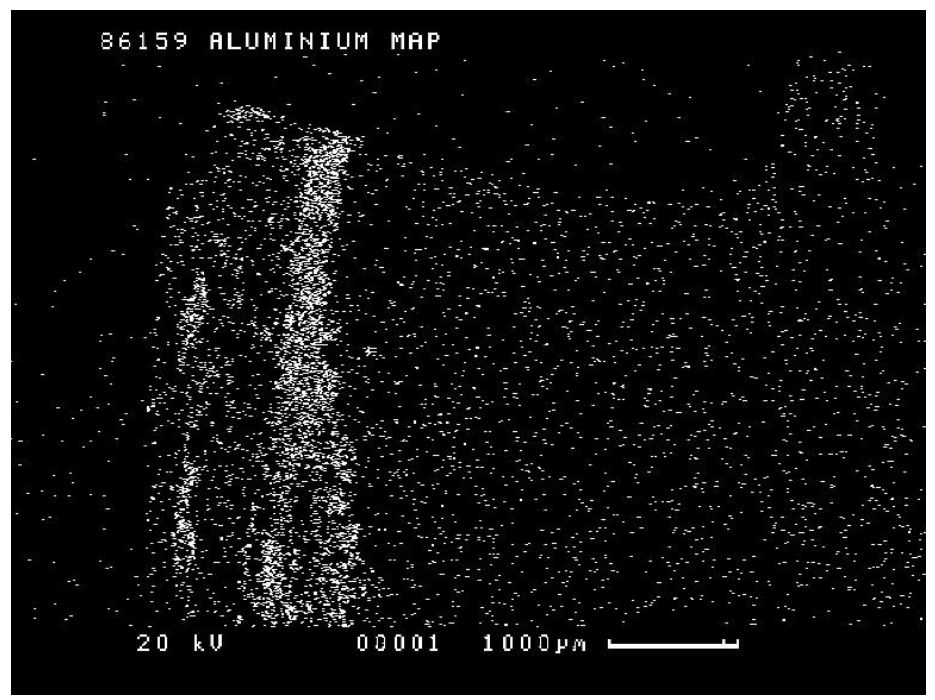

Fig.5 EDX analysis of the rivet after running at $4.5 \mathrm{kN}$ for $2.1 \times 10^{4}$ cycles.

\subsection{Topography and analysis of fretting scars}

Two distinct types of fretting zones developed on both sheets near the rivet as shown in Fig.3a). The fretting region consists of a number of two-body fretting zones and three-body fretting zones. The twobody fretting zones appear bright and are located within the central area of the scar, as shown in Fig.3.a). The three-body fretting zones appear black and contain accumulated debris. A large amount of fretting debris accumulated between the pierced and the locked sheets and became the third body in the fretting zone. The third body particles formed the boundary of the fretting scar, as shown in Fig.3a), and were also distributed within the central area of the fretting scar, as shown in Fig.3.b). A 
typical boundary between a two-body fretting region and a three-body fretting region is shown in Fig.6 which was obtained at a load of $4.5 \mathrm{kN}$ after $2.1 \times 10^{4}$ loading cycles. This presents evidence of a large lump of debris of around $25 \mu \mathrm{m}$ wide and $30 \mu \mathrm{m}$ long that accumulated during the fretting process of heading towards the three-body fretting zone. This extra third body kept involving debris migration and accumulation. The fretting debris from the three-body fretting zone has been analysed using an Energy Dispersive X-ray System, as shown in Fig.7. It can be seen that the debris was a mixed oxide of aluminium and magnesium.

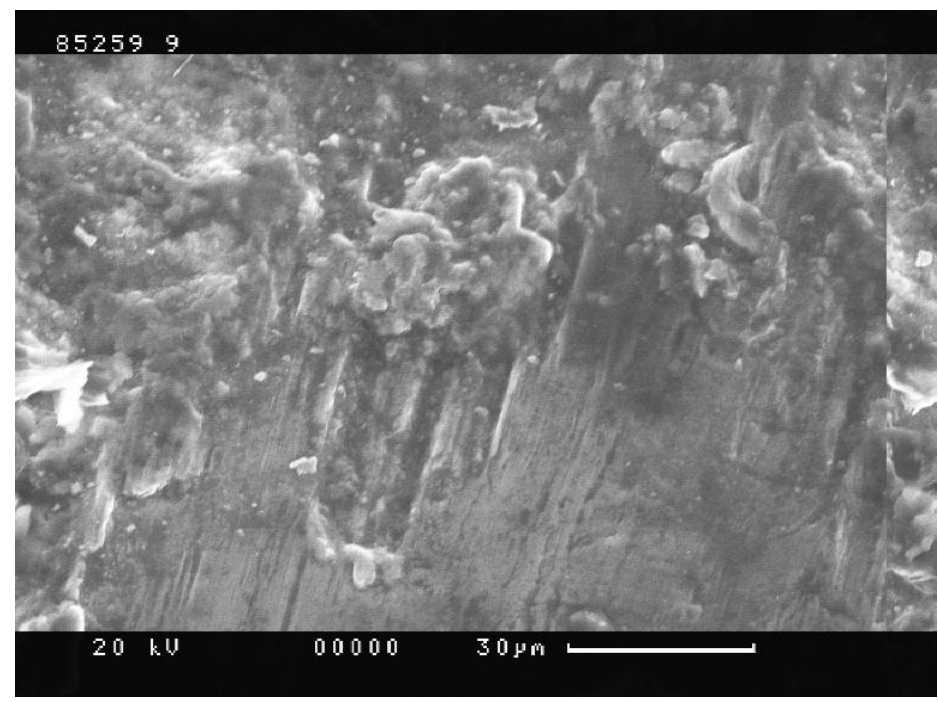

Fig.6 A typical fretting zone with the boundary between two-body and three-body fretting regions running at $4.5 \mathrm{kN}$ for $2.1 \times 10^{4}$ cvcles.

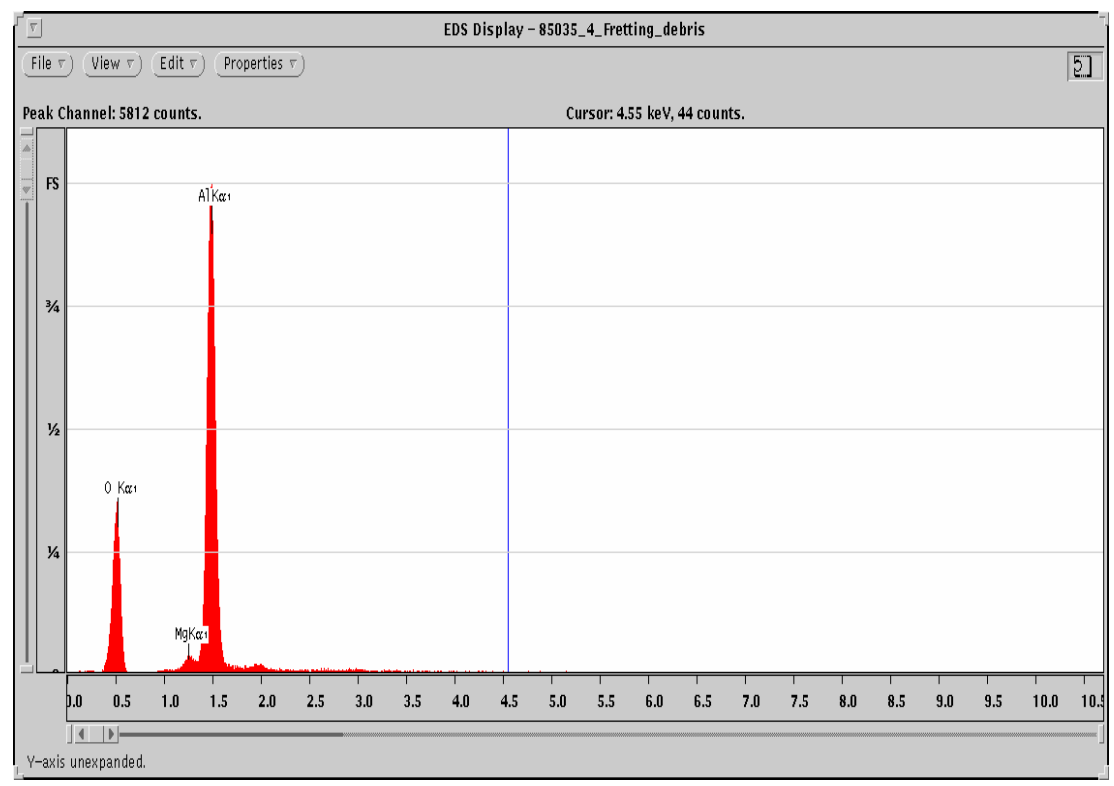

Fig.7 The spectrum of the fretting debris on a sheet. 
Fig. 8 shows typical fretting damage in a two-body fretting zone after $6.5 \times 10^{6}$ loading cycles under a maximum load of $2.7 \mathrm{kN}$. In this area many cracks have developed on the fretting worn surface. These cracks occurred in the form of closed loop. Severe spalling can be seen and it is suggested that some of the fretting debris, as shown in Fig.6, results from delamination within the two-body fretting region. As presented in Fig.8, secondary cracks existed even after delamination had occurred. Fig.9 shows a section through a joint parallel to the loading direction and the indicated contact surface on the locked sheet was obtained from interface B as shown in Fig.2. It can be seen that a typical short crack propagated in an oblique direction from the normal line of the contact surface of a locked sheet. The crack had propagated to a depth of $75 \mu \mathrm{m}$ beneath the contact surface of the sheet. The crack then changed direction towards the contact surface until it reached the surface so that a piece of debris was created.

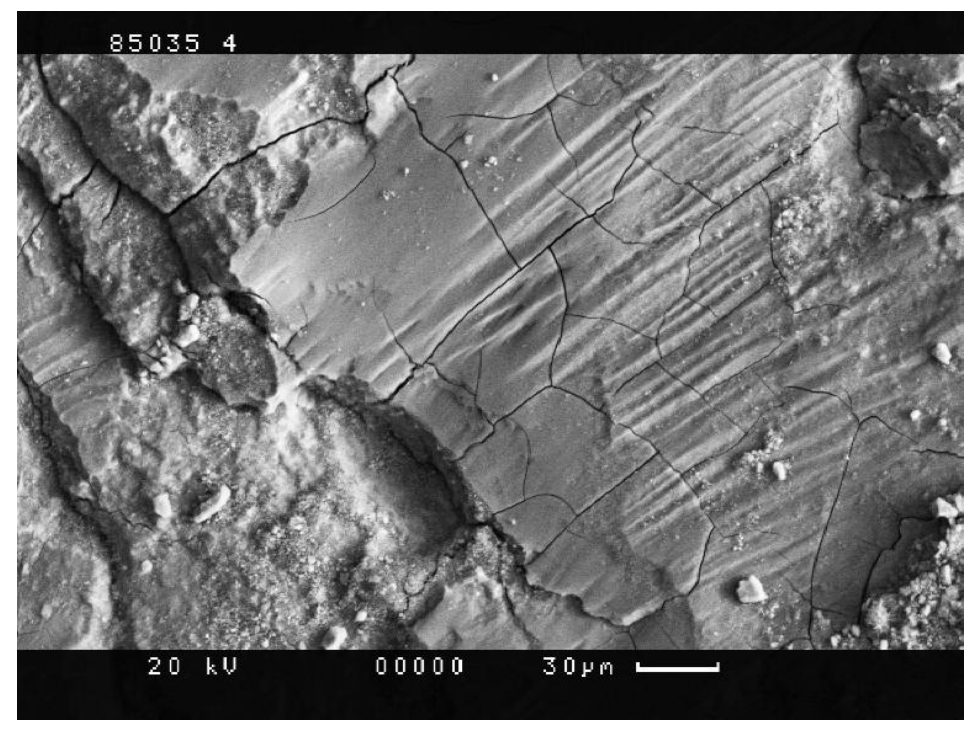

Fig.8 General fretting damage in a two body fretting region of a SPR sheet at $2.7 \mathrm{kN}$ load for $6.5 \times 10^{6}$ cycles.

Some of the cracks, instead of moving towards the contact surface, may propagate deep into the metal sheet away from the contact surface. Fig.9 shows such a typical crack that has reached a depth of approximately $400 \mu \mathrm{m}$ beneath the contact surface of the locked sheet. These types of cracks mainly formed on the contact surface of the locked sheet in contact with the rivet. Fig.10 shows a section of the contact surface on the pierced sheet from interface A in Fig.2. Figs.9-10 indicate that these deep cracks nucleated and propagated only at the contact surface of both sheets and appeared only either at the interface of the locked sheet with the rivet or at the interface between the two sheets near the rivet. The depth that the crack reached was more than $300-400 \mu \mathrm{m}$, as shown in Figs.9-10. The cracks propagated at an angle to the sliding direction instead of perpendicular to the sliding direction. 


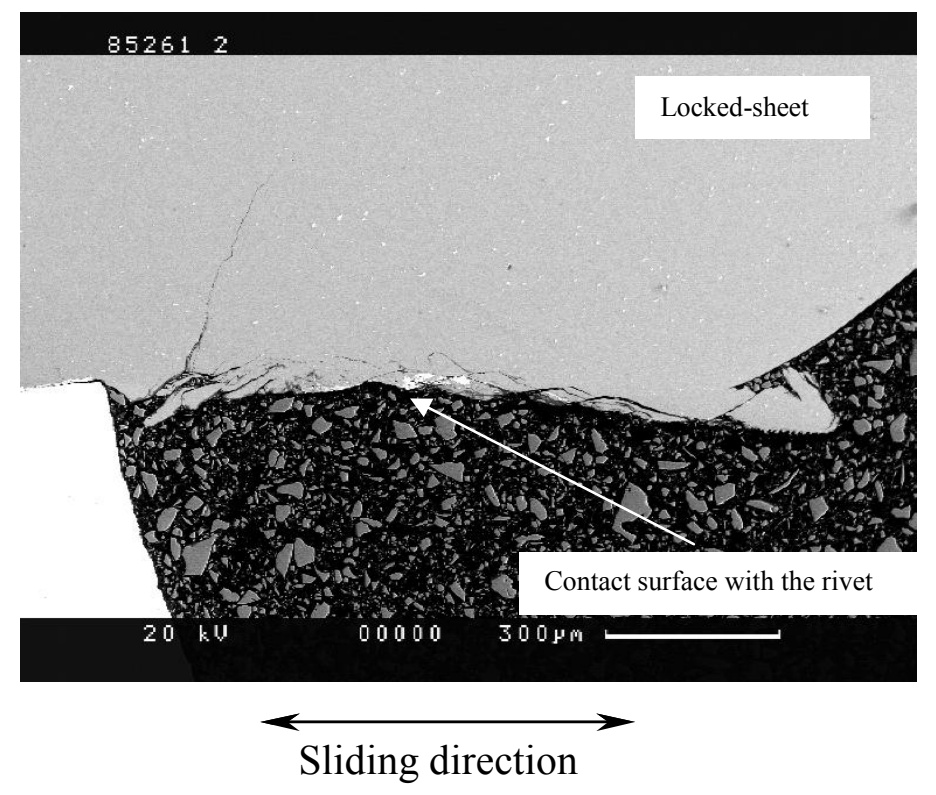

Fig.9 Section through interface $B$ parallel to the loading direction $X$ (tested at $3.6 \mathrm{kN}$ for $4.9 \times 10^{5}$ cycles).

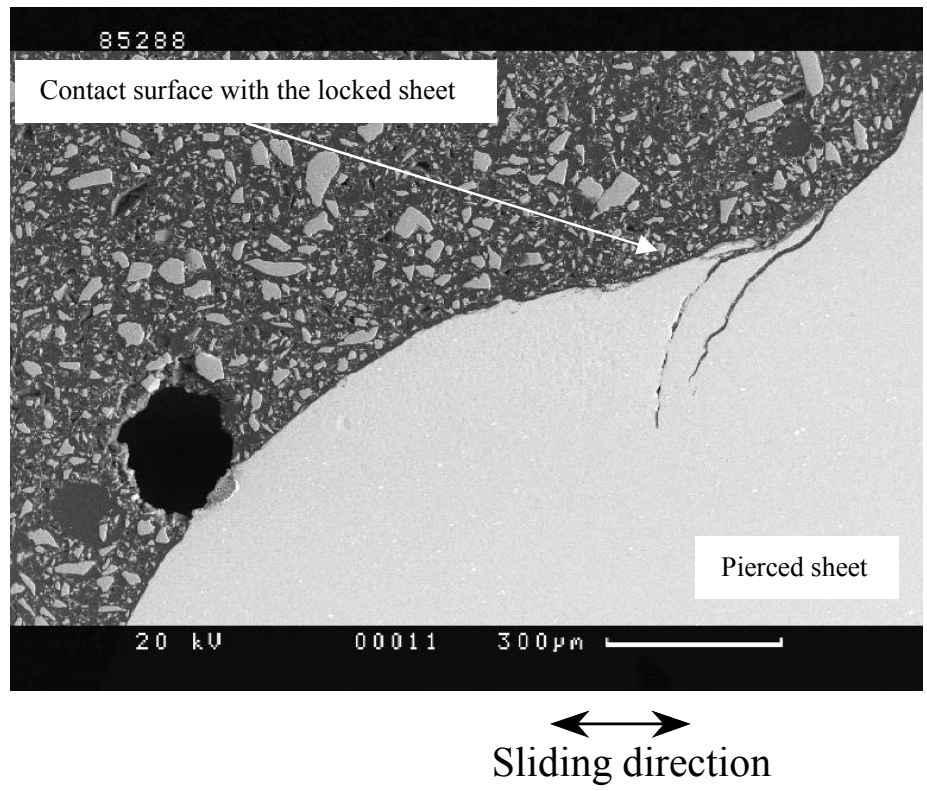

Fig.10 Section through a fretting area of a pierced sheet in interface A parallel to the loading direction (tested at $3.6 \mathrm{kN}$ for $4.9 \times 10^{5}$ cycles).

\section{Discussion}

\subsection{Two-body fretting behaviour}

As described in section 3, two-body fretting occurred at interface B between the rivet and the locked sheet and at the interface between the two sheets. As shown in Figs.9-10, two-body fretting between the interfaces resulted in two essential macro-degradation modes: surface fretting micro-cracks and fretting fatigue cracks. The crack mechanism in fretting is more complicated than in classic fatigue. 
The micro-cracks are frequently observed using SEM in the form of multi-cracks. Both micro and macro cracks may simultaneously occur in a more complex crack configuration, as shown in Figs.8-9. The micro-cracks nucleated at an angle of approximately $15^{\circ}-35^{\circ}$ with the alloy surface, propagated by fretting beneath the surface and subsequently changed the direction of propagation, as shown in Fig.9. It is suggested that the propagation of the multi-microcracks which form close to the alloy surface cause delamination and detachment of material, as shown in Fig.8, and generates debris.

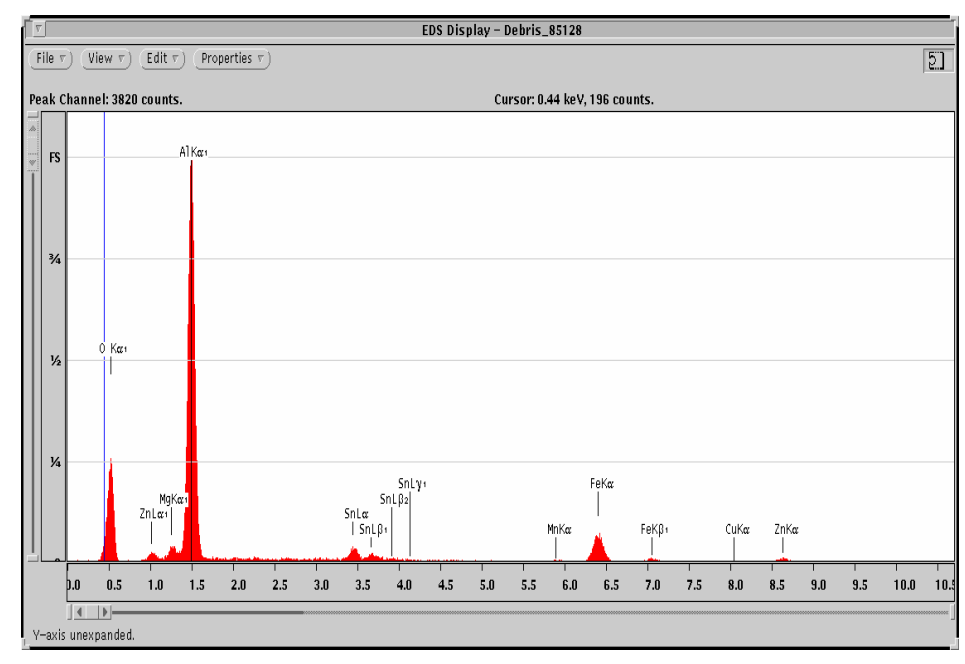

Fig.11 The spectrum of the debris on the rivet surface in contact with the locked sheet.

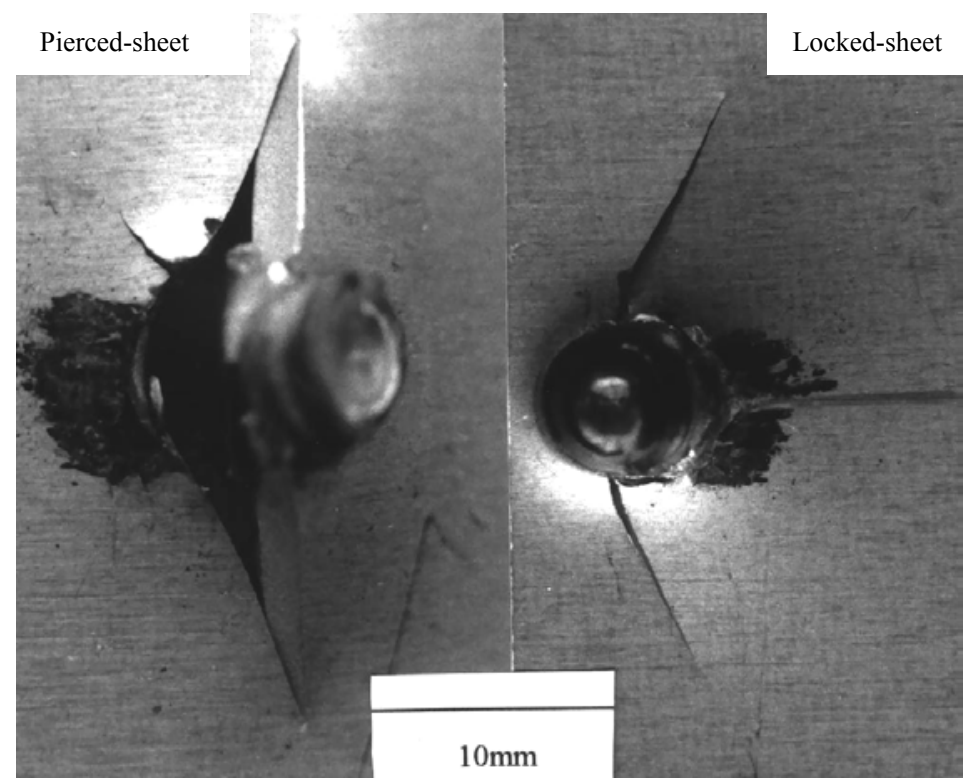

Fig.12 Fractured samples with fretting scars formed on the interface between riveted sheets for $4.9 \times 10^{5}$ loading cycles at $3.6 \mathrm{kN}$. 
However, it was observed that some micro-cracks changed the course of propagation and became macrocracks. As shown in Fig.9, one of the multi-microcracks propagated by fatigue with an angle of about $70^{\circ}$ although it initially nucleated at an angle with the surfaces of approximately $15^{\circ}-35^{\circ}$. The crack kept propagating to a depth of approximately $400 \mu \mathrm{m}$ even though delamination and detachment of material had taken place. Such macrocracks presented in Fig.10 are a type of fretting fatigue cracks since they can result in fatigue failure. The stress acting on the aluminium alloy sheet with such a fretting fatigue crack could be much higher than designed for due to a significant decrease $(25 \%$ reduction) of the sheet thickness and a high stress concentration at the crack tips. As a result, the selfpiercing riveted joint failed following propagation of a fretting fatigue crack, as shown in Fig.12.

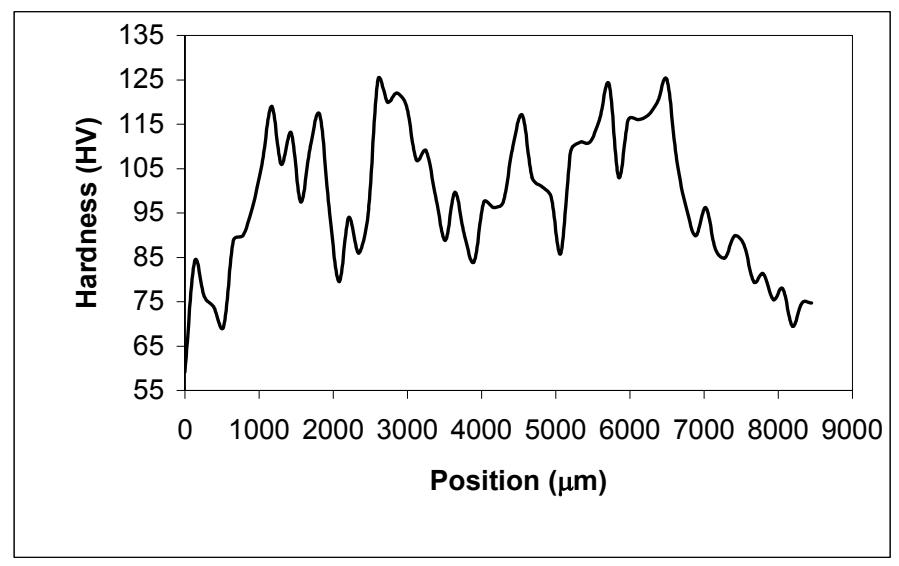

Fig.13 Microhardness distribution across a typical fretting scar near the rivet.

\subsection{Three-body fretting behaviour}

Occurrence of three-body fretting was due to the accumulation of debris generated in a two-body fretting region. As shown in Fig.6, a great amount of debris was distributed between the two original jointed surfaces of the pierced and locked sheets so that the fretting occurred on one hand between the pierced sheet and the debris and on the other hand between the locked sheet and the debris. Microhardness measurements were conducted on the substrates of the section through a fretting area, $15 \mu \mathrm{m}$ beneath the contact surface. As shown in Fig.13, the average value of the microhardness beneath the fretting area was $105 \mathrm{H}_{\mathrm{V}}$, compared with $80 \mathrm{H}_{\mathrm{V}}$ in the non-fretting region. The mircohardness within the fretting region varied from $80 \mathrm{H}_{\mathrm{V}}$ to $125 \mathrm{H}_{\mathrm{V}}$. It is suggested that these peaks of microhardness resulted from local work hardening due to high stress concentration from a local accumulation of debris. It appeared that the third body involved contact and behaved as an abrasive particle. It is suggested that three-body fretting wear was mixed with two-body fretting wear. The region covered by the third body particle was very small so that the contact stress in the region was much higher than that between the two original sheets due to stress concentration caused by the particle. Therefore, it is suggested that the third body particle would result in abrasive damage on the contact surfaces, as shown in Fig.6, when the particle migrated to the area where the contact stress was lower than that where the local accumulation of debris occurred. It can also be seen that the abrasive process of the particle generates new debris which could accumulate with more debris resulting from delamination as well as adhesion to form a new third body particle. As shown in Fig.3b), a great amount of black debris was accumulated and formed an outer boundary of the fretting scar where the contact stress was lower than in the region close to the rivet. The contact stress should be increased 
with an increase of debris accumulation and such an increase would lead to further abrasive damage in the outer boundary of the fretting scar. As a result, the debris accumulation occurred in the region further away from the rivet, therefore, the fretting expanded with an increase of loading cycles. It was evident that the fretting scar expanded with an increase of the number of loading cycles as well as an increase in test loads, as shown in Fig.3.

\subsection{Mechanism of the fretting wear of an SPR joint}

As shown in Fig.2, contact stress between the two sheets is a result of the setting force by which the joint was formed. There are at least two mechanisms of fretting: ploughing and delamination, when a cyclic tangential force $\mathrm{S}$ was applied to the joint. At the beginning of fretting, extensive ploughing due to the high contact stress between the two joined aluminium sheets caused deep scratches and considerable debris formed on the worn surface, as shown in Fig.8. Once formed, the debris oxidised rapidly and generated dark-coloured fine powders of $\mathrm{Al}_{2} \mathrm{O}_{3}$ which can be seen clearly on the worn surface shown in Fig.6 and Fig.8. As described in section 3, delamination also resulted in the formation of debris. The debris from both ploughing and delamination mixed together and transferred to the region where the contact stress was lower than that where the debris was formed initially. Since the contact surface between the two aluminium sheets was rather rough, it is inevitable that the distribution of contact stress was not even. It was noted that the contact stress around the rivet was highest and the contact stress reduced with an increase of radius distance from the rivet. Therefore, the region with low contact stress accommodated an accumulation of transferred debris from both ploughing and delamination and led to three-body fretting. The charged nature of the accumulated debris under SEM indicates that it is mainly composed of oxides as confirmed by EDX analysis.

As shown in Fig.13, there were at least five small three-body fretting zones across a section of the fretting scar. The microhardness on each three-body fretting zone was over $105 \mathrm{H}_{\mathrm{V}}$ and was 1.2 times greater than the original microhardness of the alloy $\left(80 \mathrm{HV}_{\mathrm{V}}\right)$. It is suggested that the third body, the accumulated abrasive debris, indented the contact surfaces of the joint and caused plastic scratching[18]. As a result, the third body in each small three-body fretting zone speeded up the fretting wear process around the zone so that these fretting zones could merge.

\section{Conclusions}

An investigation of the fretting behaviour of the AA5754 aluminium alloy sheet joined by self-pierce riveting has led the following conclusions.

1. Fretting wear damage is inevitable when self-piercing riveted AA5754 aluminium joints are subjected to cyclic loading.

2. Fretting wear at the interfaces between the joined sheets takes place for two-body fretting and three-body fretting. The two types of fretting were mixed within the fretting region.

3. Not all the interfaces between a rivet and a joined sheet experienced fretting. Fretting occurred in the interface between the interlock region of the rivet and the locked sheet. There is no fretting wear between the rivet and the pierced sheet.

4. Several wear mechanisms contributed to fretting damage: a ploughing process during the initial stages of fretting, followed by oxidation and delamination, then third body abrasive wear and expansion of the fretting scar during the steady-state behaviour.

\section{Acknowledgements}

The authors would like to thank both Alcan International and Textron Fastening Systems for funding and sponsoring the project.

\section{References}

[1] J. Larsson and O. Strandberg, Innovative techniques for body-in white design and assembly, Body International Quarterly, 2 (1997) 13-33. 
[2] W.S. Millers et al, Recent development in aluminium alloys for the automotive industry, Materials Science and Engineering, A280 (2000) 37-49.

[3] E.P. Patrick and M.L. Sharp, Joining Aluminum Auto Body Structure, SAE 920282, (1992) 1-8.

[4] F. Tileli, J.M. O’Sullivan, Y.K. Chen, J. Andrew and K. Denham, Dynamic response of self-pierce riveted joints, in: Bramley, A.R. Mileham, L. Newnes \& G. Owen (ed), Proceedings of the $15^{\text {th }}$ National Conference on Manufacturing Research, Pub Prof Eng Publications/I Mech E, Bath, (1999) 3-7.

[5] M. Fu and P.K. Mallick, Effect of process variables on the static and fatigue properties of selfpiercing riveted joints in aluminum alloy 5754, SAE 2001-01-0825, (2001) 117-129.

[6] C.S. Subramanian, Some considerations towards the design of a wear resistant aluminium alloy, Wear, 155 (1992) 193-205.

[7] R.B. Waterhouse, Introduction, Wear, 106 (1985) 1-4.

[8] R.B. Waterhouse, Fretting wear, ASM, Metals Handbook, Materials Park, Ohio: ASM, No.18, 1992, p.242.

[9] R.B. Waterhouse, Fretting fatigue, International Materials Review, 37(2) (1992) 77-97.

[10] C.B. Elliot III and D.W Hoeppner, The importance of wear and corrosion on the fretting fatigue behavior of two aluminum alloys, Wear, 236 (1999) 128-133.

[11] E.Rabinowicz, Friction and Wear of Materials, $2^{\text {nd }}$ Edition, Wiley, New York, 1985, p.36.

[12] P.J.E Forsyth, Occurrence of fretting fatigue in practice, in: B Waterhouse (ed), Fretting Fatigue, London Applied Science, pp,99-125, 1981.

[13] K. Lyer et al, Contribution of fretting to the fatigue and corrosion deterioration of a riveted lap joint, Structural Integrity in Ageing Aircraft, ASME, 47 (1995) 35-61.

[14] M.P. Szolwinski, Linking riveting process parameters to the fatigue performance of riveted aircraft structures, Journal of Aircraft, 37 (2000) 130-137.

[15] J. Schijve, Multi-site-damage fatigue of riveted joints, in: S N Atluri, et al (ed), Durability of metal aircraft structures, Atlanta Technology Publications, pp, 21-27, 1992.

[16] British Standard BS EN 10263-1, British Standard Publishing Limited, 2001.

[17] L. Han, Mechanical behaviour of self-piercing riveted aluminium joints, MPhil Report, University of Hertfordshire (2002).

[18] I.M. Hutchings, Tribology, Edward Arnold, London, 1992, p.135. 